\title{
Top Management Turnover and Organizational Performance: A Test of a Contingency Model*
}

George A. Boyne is a professor of public-sector management in the Business School at Cardiff University. He is also a member of the Centre for Local and Regional Government Research. His research focuses on the determinants of performance in public organizations.

E-mail: boyne@cardiff.ac.uk

Oliver James is Professor of Political Science in the Department of Politics at the University of Exeter. His current research focuses on public service performance and chief executive succession, performance reporting to citizens and users, and, more broadly, the interaction between political institutions and processes and public services.

Email: o.james@exeter.ac.uk

Peter John is the Hallsworth Chair of Governance in the School of Social Sciences, University of Manchester, where he is co-director of the Institute for Political and Economic Governance. He has held posts at Birkbeck College and at the Universities of Southampton and Keele. He has research interests in public policy, urban politics, and civic participation. He is the author of Analyzing Public Policy (1998) and Local Governance in Western Europe (2001).

E-mail: peter.john@manchester.ac.uk

Nicolai Petrovsky is an assistant professor in the Martin School of Public Policy \& Administration at the University of Kentucky. His research focuses on government performance and responsiveness.

Email: nicolai.petrovsky@uky.edu (corresponding author)

\author{
George A. Boyne \\ Cardiff University \\ Cardiff Business School \\ Aberconway Building \\ Colum Drive \\ Cardiff CF10 3EU \\ United Kingdom \\ Phone: 011-44-29-2087-5572 \\ Fax: 011-44-29-2087-4419 \\ Boyne@cardiff.ac.uk \\ Peter John \\ University of Manchester \\ Humanities Building \\ Bridgeford Street \\ Oxford Road \\ Manchester M13 9PL \\ United Kingdom \\ Phone: 011-44-16-1275-0798 \\ Fax: 011-44-16-1275-0793 \\ Peter.John@manchester.ac.uk
}

\author{
Oliver James \\ University of Exeter \\ Department of Politics \\ Amory Building \\ Rennes Drive \\ Exeter EX4 4RJ \\ United Kingdom \\ Phone: 011-44-13-9226-4504 \\ Fax: 011-44-13-9226-3305 \\ O.James@ex.ac.uk \\ Corresponding author: \\ Nicolai Petrovsky \\ University of Kentucky \\ Martin School of Policy and \\ Administration \\ 435 Patterson Office Tower \\ Lexington KY 40506-0027 \\ USA \\ Phone: 859-257-2857 \\ Fax: 859-323-1937 \\ Nicolai.Petrovsky@uky.edu
}

\footnotetext{
* Author order is alphabetical: all make an equal contribution to the article. We thank the Economic and Social Research Council Public Services Programme for support (grant number RES-166-25-0026).
} 


\title{
Top Management Turnover and Organizational Performance: A Test of a Contingency Model
}

\begin{abstract}
A crucial test of whether 'management matters' is whether changes in the team at the top of an organization make a difference. Focusing on turnover in the top team rather than change in the chief executive, in this article we argue that the impact of leadership succession is contingent on the prior performance of the organization. Our evidence on English local governments shows that changes to the top management team lead to improvements when initial performance is bad but lead to deterioration when initial performance is good. Our results support the view that high-performing organizations should attempt to retain the members of their senior management team whereas low performers should seek to replace them.
\end{abstract}




\section{Top Management Turnover and Organizational Performance: A Test of a Contingency Model}

Senior officials are widely believed to make a difference to the outputs and achievements of public organizations. Many studies of top managers in the public sector provide evidence of their role in shaping strategies, affecting implementation, and influencing performance (Boyne 2004; Brewer and Selden 2000; Hill 2005; Meier and O’Toole 2002; Rainey and Thompson, 2006; Riccucci 1995; Terry 1995; Williams and Kellough 2006). Although much attention has been devoted to the impact of individual chief executives, little research has examined the impact of the senior managers who occupy the top posts and form the team of key decision-makers in an organization. We ask whether the extent of turnover in the top management team makes a difference to organizational achievements or simply replaces those in the most senior positions with a similar group of people who have much the same impact as their predecessors. Very few studies examine the effects of staff turnover on the success or failure of public organizations, let alone the effects of top management turnover. As Meier and Hicklin $(2008$, 587) note, "examining the relationship between turnover and performance at the organizational level is in its infancy".

So why should managerial replacement matter? There are two schools of thought. One is based on the literature on the private sector, which suggests top management team turnover produces improvements in organizational performance by shaping the strategy of an organization (Boeker 1997a, 1997b; Goodstein and Boeker 1991). As we know from work on the public sector, the strategy of an organization affects its performance (Andrews et al. 2006). Moreover, the classic version of the upper echelons argument (Hambrick and Mason 1984) suggests that senior management teams are crucial determinants of organizational performance even where there are external constraints on strategic change. This view is widely supported by studies of 
top management teams in the private sector (Certo et al. 2006). According to Hambrick and Mason (1984, 193), “organizational outcomes - both strategies and effectiveness - are reflections of the values and cognitive biases of powerful actors in the organization". Top managers occupy the organizational positions with the most formal power in the organization; so when one set of top managers replaces another, this should have consequences for performance. The upper echelons model implies that a new management team might be expected to make a positive difference to performance by bringing new ideas and a better fit with the political and socio-economic environment.

On the other hand, Hannan and Freeman (1984) suggest that all organizational change, including leadership turnover, is disruptive rather than adaptive. The introduction of new members of the management team is likely to destabilize the team itself and disrupt wider organizational routines and relationships. The consequence is a reduction in organizational performance. The period before and after a succession event is widely thought to create the potential for conflict in organizations, and to distract managers and other staff from their work. In addition, external partners and funders may be reluctant to provide support until the preferences and strategies of the new incumbents become clear, which may further destabilise internal operations. The outcome is that performance falls, which makes it even harder for the new top managers to rescue the organization from the downward spiral induced by conflict and uncertainty.

Neither of these conventional perspectives, however, takes the level of performance prior to top team turnover into account, despite previous performance often being the most important predictor of current performance (Meier and O'Toole 2002). In this article we enhance the existing theoretical perspectives on the impact of top management team turnover by arguing that 
it is moderated by prior organizational performance. Where prior performance is low, we expect the positive and adaptive effects of turnover to outweigh the negative and disruptive effects; where prior performance is high, we expect the balance between these effects to be reversed and that top team turnover will lead to lower performance. This argument about the contingent effects of managerial turnover has not appeared so far in the literature on the public sector (for an application in the private sector, see Greve 1999).

The argument is best illustrated with examples. Regarding the former, a London borough that for years had languished with weak service performance and relatively unsatisfied citizens experienced several changes on the top management team. The new incumbents instituted a performance management system and re-focused the organization to improve the performance of the worst services-housing and planning. ${ }^{1}$ As an example of the latter, a unitary local government in the South of England had been achieving the second-highest performance grade for a number of years. Yet a string of successions on the top management team created a loss of organizational priorities, which in turn led to a performance drop of one grade. In short, we argue that the impact of top management team turnover is contingent on the level of public service performance that an organization has already achieved.

In this article, we test the validity of this argument with data on top-team turnover and service performance in a large sample of public organizations. First, we consider theoretical perspectives on the effects of senior management turnover and we then develop our argument that these effects are contingent on baseline organizational performance. Next we introduce the

\footnotetext{
${ }^{1}$ For organizations at the lower end of the performance spectrum, it is unusual to see a drop in performance after an increase in top management team turnover, but there is an example: The metropolitan district council of Rotherham received a Comprehensive Assessment grade of Fair (2 stars) in December 2002 but replacements of three of the five members of the top management team between April 2002 and March 2003 were followed by a performance drop to 1 star in the 2003 round of the Comprehensive Performance Assessment. This illustrates that top management turnover in poor performers is not necessarily accompanied by better results.
} 
empirical context of our analysis, and describe our variables and methods. We then present our findings before drawing conclusions for scholarship and practice.

\section{How top management turnover affects the performance of public organizations}

The operations of many public organizations are directed by a top management team which is in turn led by a chief executive. Much discussion understandably focuses on the role of the chief executive, partly through the public focus on incoming leaders who are often seen as the new brooms, such as new school district superintendents, new city managers, and new chief executives of hospitals. But there is a growing research literature on leadership qualities exercised more generally in organizations. One example is Brewer and Selden (2000), who use data from the 1996 Merit Principles Survey, covering 18,183 federal employees in twenty-three agencies. Another is Moynihan and Pandey's (2005) survey of 274 state government health and human services officials, which uses regression analysis on self-reported performance scores. Studies that go beyond a focus on the chief executive implicitly accept that leadership in public organizations is distributed rather than concentrated in a single individual (Carson et al. 2007; Lawler 2008). Moreover, a focus on the management team recognizes the pluralism of many public organizations, which are federated into service bureaucracies that one sole chief executive may be unable to control. A concerted effort by the whole senior management team is likely to be required to effect change across organizational departments and sub-units with different values and professional norms. Chief executives typically have roles that take them away from direct control over the bureaucracy, in particular dealing with external constituencies. Members of the top management team on the other hand have responsibility for the delivery of services and hence have a direct influence on performance. 
So the senior managers matter. But in what way do they matter and with what implications for performance? The literature on private-sector organizations contains mixed results, with some evidence suggesting a positive effect of top management team turnover. Looking at a cross-sectional sample of Fortune 500 companies, Davidson, Worrell, and Cheng (1990) find that turnover at the top is associated with positive market reactions. However, other evidence suggests the opposite. Kacmar et al. (2006) find that increases in managerial turnover in a fast food chain are related to reductions in performance (both directly and through concomitant increases in staff turnover) due to the learning costs of the new managers, though it should be noted that this refers to operational rather than top managers. Similarly, Shen and Cannella (2002) find that the turnover of senior executives has a negative effect on return on assets in a sample of 228 companies. Another study (Warner, Watts, and Wruck 1988) concludes there is no evidence of a relationship between top management change and subsequent stock performance. Thus the available evidence on private firms is a mix of positive, negative and insignificant effects of top management team turnover. None of these studies, however, takes the potentially moderating effect of baseline performance into account.

In the public sector context, there is a debate between proponents of organizational stability, including personnel stability, and those who advocate change because it reflects the ability to innovate and adapt (O'Toole and Meier 2003; Boyne and Meier 2009a). New people in charge could bring about a change in strategy, skill-set, and willingness to modify the organization. In particular, changes amongst the top management team might help an organization adapt to new circumstances and consequently lead to higher performance. Stability might ossify organizations whereas change allows bureaucracies to respond to new pressures. 
In the New Public Management literature, new senior bureaucrats may be associated with reform and new ideas for bringing about service improvement (e.g. Osborne and Hutchinson 2004). However, they might also have the opposite effect: The disruption induced by the departure of specialists among the top management could lead to a drop in organizational performance (Hill 2005). It is also possible that such changes are largely ritual, for scapegoating purposes or to demonstrate the organization's agility with stakeholders, but without a performance effect. The causal mechanism is the way in which existing bureaucrats use their experience and knowledge of 'where the bodies are buried' to ensure the organization maintains or improves upon existing levels of performance. New bureaucrats need to find out what works and recruit other more junior officials as followers who can implement their strategies. A new management team may not have immediate access the informal networks within organizations and cannot rely on top-down command and control strategies. It is therefore possible thatcontrary to the dictates of the New Public Management—stability, including top team stability, is a source of good organizational performance. There is evidence in accordance with this point of view in research on school superintendents (O’Toole and Meier 2003, Hill 2005).

Rather than coming to a theoretical impasse, it is possible to argue that the effects of top management team turnover are positive or negative depending on organizational circumstances. This view draws directly on contingency theory, which suggests that managerial effects on performance vary with environmental and organizational contexts (Donaldson 1996). In particular, turnover may have very different consequences depending on whether the organization is already performing well or poorly. For high performing organizations, turnover can be damaging, creating change when the organization has learnt to play the game and losing key personnel who created the success in the first place. The new person or team in post has 
much to learn and a lot to lose, and the disruption may cause the beginnings of a downward spiral, such as loss of staff and reputation, which feed back to push performance downwards.

Similarly, the top management team in an organization that is performing poorly may lack the inclination, skills or political support to achieve higher performance. In this case, new blood in the top team may be required to reinvigorate the organization and improve the standard of its services. This view is consistent with research on organizational turnaround that finds new leadership to be an important component of recovery from failure (Boyne and Meier 2009b). Top managers in failing organizations may suffer from 'threat-rigidity' - a loss of the ability to adjust their decisions to deal flexibly with a crisis (Staw et al. 1981) — and be unable or unwilling to pursue the new strategies that are required to improve performance (Hambrick and D'Avenni 1992). New senior appointments, on the other hand, are free of the shackles of the past strategies that have led to poor performance, and are more likely than their predecessors to scan the environment for new ideas and opportunities (Cho 2006). For these reasons we hypothesize that management team turnover does affect performance per se, but can improve the performance of poor performers and depress that of high performers. In other words, prior performance levels moderate the effects of top team turnover on subsequent performance changes.

\section{Data and methods}

Our data are a panel of principal English local governments (London and metropolitan boroughs, shire counties, and unitary local governments). They have the primary service provision responsibilities in the English local government system. English local governments are often considered a low-discretion industry in Finkelstein and Hambrick's (1990) terms because the central government tightly regulates and supervises them (Stoker 2004; Wilson and Game 2006). 
Consequently, we are putting the classic upper echelons argument to a particularly tough test. If we do find systematic relationships between the turnover of top management teams and organizational performance in English local government, it is likely to exist in many public organizations where senior management teams enjoy more discretion.

Our approach guards against an alternative explanation for a relationship between top management team turnover and organizational performance: Since 'when you're at the top, the only way is down' and vice versa for low performance, regression to the mean might appear to be a threat to the validity of our research. Nevertheless, as we explain below, we always compare the rates of change in performance with and without top management team turnover. Our estimates reflect the change in performance above and beyond what would have occurred in the absence of turnover, which ensures that our research is not endangered by regression to the mean.

We collected the data on top team turnover from local government web pages, all editions of the Guardian Local Authority Directory, archival data from 2004 provided by Oscar Research Ltd, various editions of the Municipal Yearbook, and the Audit Commission. Our panel has five waves, from the 2002/03 financial year up to and including 2006/07. ${ }^{2}$ Using a panel provides three important advantages for our analysis: (i) we are able to use variation over time to test dynamic hypotheses; (ii) we can control for past performance; and (iii) we can exclude all alternative explanations based on time-invariant differences between local governments, as we further explain below. We now discuss our variables. Summary statistics appear in Table A1 in the appendix.

Our dependent variable is organizational performance. We estimate two different sets of models. The first set uses the core service performance score as the indicator of performance;

\footnotetext{
${ }^{2}$ In English local government, the financial year runs from April 1 to March 31.
} 
the second set analyzes the Comprehensive Performance Assessment ratings. Both indicators stem from an extensive set of local government measures developed and monitored by the Audit Commission, which offers an unusual opportunity to assess top management theory using performance variables. The Audit Commission carries out checks of the accuracy of the data collected by the local governments as part of the system, and sends auditors and inspectors to make judgments about broader aspects of performance (Audit Commission 2002; Broadbent 2003).

Dependent variable 1: core service performance score

If top team change matters then its effect should be observable at the level of the organization as a whole. Thus it is important to use broad dependent variables that cover all major functions and dimensions of performance. Our first dependent variable is the core service performance score, a summary measure of performance theoretically ranging from 0 (worst) to 100 (best). It is based on a range of performance information, including Best Value Performance Indicators and covers all major services (e.g. education, housing, social services, transport, planning, waste collection) and a variety of dimensions of performance such as service quantity, quality and effectiveness.

\section{Dependent variable 2: Comprehensive Performance Assessment}

Our second indicator of performance is the Comprehensive Performance Assessment (CPA). The CPA is based equally on the service performance score and judgments by Audit Commission inspectors on a local government's 'ability to improve.' It is a summary rating of a local government's performance. There are five levels: Poor/0 stars, Weak/1 star, Fair/2 stars, Good/3 stars, and Excellent/4 stars. The CPA is a highly visible and publicized performance 
rating that is taken seriously by central government (in applying sanctions to low-performing local governments) and by local politicians who increasingly wish to appoint new senior managers who can make a difference to the grade that is achieved (Audit Commission 2008). The correlation between the CSP and the CPA is about .67, that is, $44 \%$ of the variance in the CSP is explained by the CPA and vice versa.

Key explanatory variable: top management turnover

The top management team in English local governments is defined as the echelon of service directors or chief officers who report directly to the chief executive. This is the standard approach to defining the top management team in prior studies (Carpenter et al. 2004). A typical top management team includes a Director of Finance, a Director of Legal Services, a Director of Children's Services, a Director of Adult Services, and a Director of Corporate Services. The first three posts are mandated by legislation ${ }^{3}$ and exist in every principal local government. Many local governments have more positions than the three required on their senior management team. Based on this definition, we collected information on positions on the top management team and the names of the people who fill them. We use this information in developing our indicator of top management team turnover:

Turnover rate $=$

Number of new names on top management team

\section{Number of positions mentioned}

In this definition, the denominator is the number of positions on the top management team in a given local government in a given year. The top management team turnover rate reflects the extent of change in the formal positions at the top of the organizational hierarchy. We include

\footnotetext{
${ }^{3}$ The first two posts are mandated by the Local Government Act 2000 and the third post is mandated by the Children's Act 2004.
} 
one- or two-year lags of this variable in our specifications. The reason that we always at least use a one-year-lag is that performance measurements for a given year, e.g. the Comprehensive Performance Assessment ratings for 2002, are based on data and inspections from the previous financial year. The specifications using a two-year lag test for the possibility that new appointments to the top management team might take a year or more to have an impact on organizational performance.

It could be argued that turnover rate of management is endogenous, with poor performance bringing about subsequent change in management team personnel. Whilst this is likely to be the case, turnover is much less likely to be set by future performance so, for our models, endogeneity is not likely to be problematic. ${ }^{4}$

\section{Control variables}

We include a number of controls for factors known to generally affect public service performance. The first and most important control is past performance. Theory suggests that organizations are autoregressive systems (O’Toole and Meier 1999) and therefore omitting past performance from equations explaining performance would lead to biased findings. We include prior performance both as a base term and as a moderator of the impact of senior management turnover. As argued above, it is likely that performance effects of changes in top management depend on the baseline performance of the organization preceding the change in the top management team turnover rate. We expect organizations performing highly before the change in top management turnover to experience a drop in performance and organizations initially performing poorly to experience a rise in performance. In addition, in all our models, by virtue

\footnotetext{
${ }^{4}$ We checked this assertion by regressing the top management team turnover rate on the first lead and the second lead of the Core Service Performance Score, both separately and jointly, and controlling for local government characteristics. In no case could the null hypothesis be rejected.
} 
of our estimation technique we automatically control for (relatively) fixed differences between governments such as population and deprivation. Further, we control for the presence of a chief executive succession in the same year as the top management team turnover rate is measured. ${ }^{5}$ This takes account of the possibility that any top team effects we find are simply a proxy for unmeasured chief executive effects. We also control for unusual common shocks in individual years, such as changes to the performance assessment system used by the Audit Commission.

Our specification is:

Performance $_{i t}=\mathrm{b} 0+\mathrm{b} 1$ performance $_{\mathrm{i}, \mathrm{t}-1}+\mathrm{b} 2$ turnover rate $_{\mathrm{i}, \mathrm{t}-1}$

$+\mathrm{b} 3$ (turnover rate $\times$ high baseline performance) ${ }_{i, t-1}$

+ b4 (turnover rate $\times$ low baseline performance) ${ }_{i, t-1}$

$+\mathrm{b} 5$ chief executive succession $_{\mathrm{i}, \mathrm{t}-1}+\mathrm{u}_{\mathrm{i}}+\mathrm{v}_{\mathrm{t}}+\varepsilon_{\mathrm{it}}$,

where $\mathrm{u}_{\mathrm{i}}$ covers all unobserved, time-invariant (within our study) characteristics of local government $\mathrm{i}$ (e.g. a persistent level of deprivation), $\mathrm{v}_{\mathrm{t}}$ covers all common shocks in year $\mathrm{t}$ (such as the extra demands on anti-terrorism preparedness in recent years), and $\varepsilon_{\text {it }}$ is a random shock experienced by local government in year $t$, such as flooding within that local government jurisdiction in a rainy summer.

Since we have an autoregressive specification - i.e. we control for past performance-we need to take special care in estimating our models. In the presence of a lagged dependent variable, pooled ordinary least squares (OLS) is consistent only if there is no unobserved heterogeneity-time-invariant differences between local governments that are not fully measured - and no serial correlation. If there is unobserved heterogeneity, the coefficient on the past value of performance will tend to be exaggerated. This is not a major problem necessarily,

\footnotetext{
${ }^{5}$ As a robustness check, we also estimated models where the impact of the top management team turnover rate is moderated by the presence of a chief executive succession. Yet these models do not perform better statistically than the ones we report in this article.
} 
but might make it harder to find evidence in accordance with the top management team turnover hypotheses. Therefore we use an instrumental variables estimator that allows us to control for unobserved heterogeneity while removing any bias that this might have induced in the coefficient on the lagged dependent variable. This estimator was developed by Anderson and Hsiao (1981). While it is designed for continuous dependent variables, it is also the best choice for the Comprehensive Performance Assessment since dynamic estimators for ordered dependent variables do not exist. ${ }^{6}$

We test for different specifications by lagging the variables and interacting our top team turnover measures with previous levels of performance. We divide baseline performance into three groups: high, medium and low. For the core service performance score, low baseline performance is defined as one standard deviation below the grand mean or worse, and high baseline performance as one standard deviation above the grand mean or better. Everything that lies within one standard deviation of the grand mean of the core service performance score is defined as medium baseline performance. In our data set, the mean of the core service performance score is approximately 68.5 and the standard deviation is approximately 8.5 . Consequently, all observations with a core service performance score above 77 are classified as high baseline performance ( $15 \%$ of observations) and all observations with a core service performance score below 60 are classified as low baseline performance (13\% of observations). The remaining $72 \%$ of observations are classified as having medium-level baseline performance.

\footnotetext{
${ }^{6}$ A potential problem of this estimator is that, while it is consistent, it may not perform well in samples of limited size, such as ours. One simple check for this is to verify whether the Anderson-Hsiao estimates lie between those obtained by fixed effects with a lagged dependent variable, and ordinary least squares with a lagged dependent variable, or at least not significantly outside this range. The rationale for this check is that in the presence of unobserved heterogeneity, these two estimators are inconsistent. The estimated coefficients on the lagged dependent variable tend to be small in the former case and too large in the latter (see Bond 2002, 144). In all our models, the range between these two coefficient estimates is indeed large, and all of our Anderson-Hsiao lagged dependent variable coefficient estimates lie either roughly at mid-point between the fixed effects and the OLS estimate (all models with the CSP as the indicator of performance and the additive models with the CPA as the indicator of performance) or right at the OLS estimate (the multiplicative models with the CPA as the indicator of performance).
} 
For the Comprehensive Performance Assessment, low baseline performance is defined as a rating of 0 stars (Poor) or 1 star (Weak). High baseline performance is defined as a rating of 4 stars (Excellent). Comprehensive performance assessment ratings of 2 stars (Fair) or 3 stars (Good) are defined as medium baseline performance. ${ }^{7}$ In this way, $23 \%$ of observations are classified as high baseline performance and $13 \%$ are classified as low baseline performance, with the remainder (64\% of observations) classified as having medium-level baseline performance. In our interactive models, we include dummy variables for high performance and low performance. Medium performance is the base (excluded) category. In the models where the top management team turnover rate is moderated by baseline performance (Tables 3 and 4), the effect of an increase in the top management team turnover rate depends on the level of baseline performance. In organizations initially at medium performance, the effect of top management team turnover is the coefficient estimate on the base term of chief executive succession. In organizations initially at high or low performance, the effect of an increase in the top management team turnover rate is the sum of two coefficients: the coefficient estimate on the base term of the top management team turnover rate and the coefficient estimate on the product term of the top management team turnover rate and high (low) baseline performance.

Descriptive statistics for all of the variables in our models are shown in Appendix table A.1. These show that the average rate of annual turnover for members of the top management team in English local government is almost 20 per cent. In some local governments in some years the turnover rate is zero, whereas in others all of the membership changes from one year to

\footnotetext{
${ }^{7}$ As a robustness check, we also examined the following alternative classifications: (i) low baseline performance: 0 stars (Poor), 1 star (Weak), or 2 stars (Fair), medium baseline performance: 3 stars (Good), high baseline performance: 4 stars (Excellent); and (ii) low baseline performance: 0 stars (Poor) or 1 star (Weak), medium baseline performance: 2 stars (Fair), high baseline performance: 3 stars (Good) or 4 stars (Excellent). The results are very similar. As a further robustness check, we estimate models with a continuous moderating variable, which provides qualitatively similar results. We report these findings in the appendix.
} 
the next. We now proceed to evaluate whether these variations in the turnover rate are associated with organizational performance.

\section{Findings}

Tables 1-4 show dynamic models explaining organizational performance. Tables 1 and 2 test for an unconditional effect of the top management team turnover rate, while tables 3 and 4 test for the effect of the top management team turnover rate moderated by baseline performance. The dependent variable in tables 1 and 3 is the core service performance score, and the dependent variable in tables 2 and 4 is the Comprehensive Performance Assessment. For both dependent variables, we examine the effects of both a one-year and two-year lagged effects of top management turnover on performance. ${ }^{8}$

As expected, the models in tables 1 and 2 show that there is no unmoderated overall effect of top management team turnover on organizational performance. The average effect of senior management turnover across the range of performance is insignificantly different from zero. This average effect is, however, masking different effects at different levels of baseline performance. Three of the four specifications in tables 3 and 4 contain findings in accordance with the hypothesis that top management team turnover is adaptive at low levels of baseline performance but disruptive at high levels, with little impact at middle levels of baseline performance.

In model 3.2 in table 3 an increase of ten percentage points in the turnover rate is associated with a 0.8 -point increase in the core service performance score for initially low-

\footnotetext{
${ }^{8}$ As a robustness check, we tested whether the extent of top management team turnover in a 2-, 3, and 4-year period up to the year the top management team turnover rate is measured moderates its effect. In two thirds of these models the null hypothesis of no such interaction effect could not be rejected, and in the remainder of these models the findings were mixed.
} 
performing organizations and a 1.4-point decrease for initially high-performing organizations, while there is no statistical relationship for organizations initially performing at a medium level. These coefficients suggest the negative impact of turnover in high-performing organizations is almost twice as strong as the positive impact in low-performing organizations. In models 4.1 and 4.2, an increase of ten percentage points in the turnover rate is associated with a tenth of a star increase in the Comprehensive Performance Assessment rating for initially low-performing organizations and a tenth of a star decrease for initially high-performing organizations. Again, there is no statistical relationship for organizations initially performing at a medium level, which suggests that the disruptive and adaptive effects of top management change roughly cancel each other out.

There is one specification that provides neither support for, nor evidence against, the hypothesis that top management team turnover is beneficial at low levels of baseline performance but disruptive at high levels. In model 3.1 there is no statistically significant shortrun effect of managerial turnover on core service performance. It could be that whilst turnover of managers can bring about change likely to affect the judgments of inspectors and auditors contained in the 'ability to improve' element of Comprehensive Performance Assessment, for example by making auditors aware of their plans and giving an impression of confidence, it takes longer for actual service performance scores to be turned around.

Overall, our findings are in accordance with our theoretical argument that suggests that top management turnover is beneficial at low baseline levels of organizational performance and harmful at high baseline levels, while it is of ambiguous or no effect at medium levels of baseline performance. The evidence is consistent with the view that placing unsuccessful organizations under new management can make a positive difference to performance that outweighs any short- 
term disruption to structures and processes. On the other hand, top management turnover is harmful to high performers. This may be because the new members bring strategic assumptions that do not fit the organization, because they take some time to gel with their more established peers, or because their appointment leads to uncertainty elsewhere in the organization (or in the minds of managers in partner organizations).

Amongst our control variables, only past performance and the year dummies are related to current performance across all specifications. The different intercepts in different years serve as a reminder that simply pooling a number of cross-sections without adjusting for differences in the overall environment from year to year would lead to biased findings. The presence or absence of a chief executive succession in the same year as the top management team turnover rate is measured generally does not affect performance. Thus top team turnover is not simply a proxy for chief executive succession. Our results are consistent with a model of distributed leadership across the whole top management team, rather than a model of heroic leadership that emphasizes the effect of the chief executive alone.

\section{Conclusions}

As is so often mentioned in the literature on organizational performance in the public sector, 'management matters'. There are few better indicators of the potential for management to make a difference than changes in the team at the top of an organization. This creates a powerful variable to test the effect of management on the performance of public sector organizations. But there is a dispute about the way in which new managers do in fact matter-do they put things right or do they undo the good work of their predecessors? 
Our analysis is innovative. Not only do we examine the effects of turnover in top management teams, we also we examine the contingent effect of baseline performance rather than seeking a general relationship as characterizes much of the rest of the literature on managerial succession. Our evidence on English local government shows that top management teams matter and that universal conclusions on the impact of turnover are inappropriate. Indeed, had we tested the impact of top team turnover in the absence of the prior performance moderator we might have concluded that new managers make no difference to the quality of public services. Instead we find that changes to the top management team lead to improvements when initial performance is bad but lead to deterioration when initial performance is good. In addition, the contingent effects of top management team turnover on direct measures of service performance are not symmetrical. The damage to high performing organizations' Core Service Performance score outweighs the benefits to low performing organizations. If the top management team turnover rate increases by 0.2 (twenty percentage points)—which translates into one new senior manager on a team that is about average-sized - then the Core Service Performance score declines on average by 2.72 in the former case and rises by 1.25 in the latter, with the score ranging from 40 to 90 overall between the worst and best performers in the dataset. These estimates are obtained by dividing the marginal effects provided in Table 3, which are for an increase in the turnover rate of 1 (i.e. going from zero to one-hundred percent turnover), by five to obtain the effect of an increase by twenty percent.

Our findings, while applicable to many other public organizations, do not necessarily carry over to all public service contexts. School districts in deprived urban areas tend to be marked by a high turnover of superintendents and limited improvements. Hess (1999) suggests that in urban school districts - public organizations with high task difficulty and where little is 
known about the technology to improve outcomes - superintendents will focus on symbolic ephemeral innovations. Superintendents need to produce results, and in a situation of great uncertainty such as this, the best available proxy for results is the amount of activity (Hess 1999, 39-40). Yet the breadth and depth of performance measurement in organizations such as English local governments shifts the emphasis towards the substance of performance, not just its appearance.

A broader contribution of this study is that we have highlighted that the effects of organizational change are moderated by prior performance. The performance history of an organization makes a difference to the impact of managerial turnover on its subsequent success or failure. There is likely to be a broader lesson here for evaluating the effects of other organizational interventions, such as the introduction of new structures, processes and strategies. The impact of each of these, too, seems likely to be contingent on an organization's existing performance. Future studies of organizational change in the public sector should, therefore, incorporate the contingencies associated with prior performance in their research designs.

Our study has opened up a large research agenda on the performance consequences of top team turnover. Qualitative case studies of senior management change in high and low performing organizations could helpfully trace through the nature and balance of adaptive and disruptive effects, and provide important insights on precisely how top management turnover makes a difference to performance. A further direction for research would be to examine the relationship between top management team turnover and subsequent change in outputs and outcomes in organizations at the forefront of technological change, for instance regulatory agencies. There, we expect the relationship to be attenuated because top management team turnover may achieve no more than maintaining the agency's capacity to keep up with the state 
of the art in its field. Large-N studies in other nations, levels of government, and service areas would also be useful to establish whether the moderating effect of prior performance is generalizable to other contexts. These finding may be of use in the literature that examines the causes of turnover (e.g. Moynihan and Landuyt 2008) as there may be feedback from performance to turnover itself. 


\section{References}

Anderson, T.W. and Cheng Hsiao. 1981. "Estimation of Dynamic Models with Error Components." Journal of the American Statistical Association 76 (375): 598-606.

Andrews, Rhys, George A. Boyne, and Richard M. Walker. 2006. "Strategy Content and Organizational Performance: An Empirical Analysis." Public Administration Review 66 (1): 5263.

Audit Commission. 2002. The Final CPA Assessment Framework for Single Tier and County Councils. London: Audit Commission.

Audit Commission. 2008. Tougher at the Top? London: Audit Commission.

Boeker, Warren. 1997a. "Strategic Change: The Influence of Managerial Characteristics and Organizational Growth." Academy of Management Journal 40 (1): 152-170.

Boeker, Warren. 1997b. "Executive Migration and Strategic Change: The Effect of Top Manager Movement on Product-Market Entry." Administrative Science Quarterly 42 (2): 213-236.

Bond, Stephen R. 2002. "Dynamic Panel Data Models: A Guide to Micro Data Methods and Practice." Portuguese Economic Journal 1 (2): 141-162.

Boyne, George A. 2004. Explaining Public Service Performance: Does Management Matter? Public Policy and Administration 19(4): 110-17.

Boyne, George A. and Kenneth J. Meier. 2009a. Environmental Turbulence, Organizational Stability and Public Service Performance. Administration and Society 40(8): 799-824.

Boyne, George A. and Kenneth J. Meier. 2009b. Environmental Change, Human Resources and Organizational Turnaround. Journal of Management Studies 46 (5): 835-863.

Brewer, Gene and Sally Coleman Selden. 2000. Why Elephants Gallop: Assessing and Predicting Organizational Performance in Federal Agencies. Journal of Public Administration Research and Theory 10(4): 685-712.

Broadbent, Jane. 2003. "Comprehensive Performance Assessment: The Crock of Gold at the End of the Rainbow?" Public Money and Management 23 (1): 5-7.

Carpenter, Mason, Marta Geletkanycz, and Gerard Sanders. 2004. Upper Echelons Research Revisited: Antecedents, Elements, and Consequences of Top Management Team Composition. Journal of Management 30(6): 749-78.

Carson, Jay, Paul Tesluk, and Jennifer Marrone. 2007. Shared Leadership in Teams: An Investigation of Antecedent Conditions and Performance. Academy of Management Journal 50(5): 1217-34. 
Certo, Trevis, Richard Lester, Catherine Dalton, and Dan Dalton. 2006. Top Management Teams, Strategy and Financial Performance: A Meta-Analytic Examination. Journal of Management Studies 43(4): 813-39.

Cho, Theresa S. 2006. The Effects of Executive Turnover on Top Management Team's Environmental Scanning Behaviour after an Environmental Change. Journal of Business Research 59 (10-11): 1142-50.

Davidson, Wallace N. III, Dan L. Worrell, and Louis Cheng. 1990. Key Executive Succession and Stockholder Wealth: The Influence of Successor's Origin, Position, and Age. Journal of Management 16(3): 647-64.

Donaldson, Lex. 1996. For Positivist Organization Theory: Proving the Hard Core. London: Sage.

Finkelstein, Sydney and Donald C. Hambrick. 1990. Top-Management-Team Tenure and Organizational Outcomes: The Moderating Role of Managerial Discretion. Administrative Science Quarterly 35(3): 484-503.

Furtado, Eugene P. H. and Vijay Karan. 1990. Causes, Consequences, and Shareholder Wealth Effects of Management Turnover: A Review of the Empirical Evidence. Financial Management 19(2): 60-75.

Goodstein, Jerry and Warren Boeker. 1991. "Turbulence at the Top: A New Perspective on Governance Structure Changes and Strategic Change." Academy of Management Journal 34 (2): 306-330.

Greve, Henrich R. 1999. The Effect of Core Change on Performance: Inertia and Regression toward the Mean. Administrative Science Quarterly 44(3): 590-614.

Hambrick, Donald C. and Phyllis A. Mason. 1984. Upper Echelons: The Organization as a Reflection of Its Top Managers. Academy of Management Review 9(2): 193-206.

Hambrick, Donald and Richard D'Avenni. 1992. Top Team Deterioration as part of the Spiral of Large Corporate Bankruptcies. Management Science 38(10): 1445-66.

Hannan, Michael T. and John Freeman. 1984. Structural Inertia and Organizational Change. American Sociological Review 49(2): 149-64.

Hess, Frederick M. 1999. Spinning Wheels: The Politics of Urban School Reform. Washington, DC: Brookings Institution Press.

Hill, Gregory C. 2005. The Effects of Managerial Succession on Organizational Performance. Journal of Public Administration Research and Theory 15(4): 585-97. 
Kacmar, K. Michele, Martha C. Andrews, David L. Van Rooy, R. Chris Steilberg, and Stephen Cerrone. 2006. Sure Everyone Can Be Replaced... But at What Cost? Turnover as a Predictor of Unit-Level Performance. Academy of Management Journal 49(1): 133-44.

Lawler, John. 2008. Individualization and Public Sector Leadership. Public Administration 86(1): 21-34.

Meier, Kenneth J. and Alisa Hicklin. 2008. Employee Turnover and Organizational Performance: Testing a Hypothesis from Classical Public Administration. Journal of Public Administration Research and Theory 18(4): 573-590.

Meier, Kenneth J. and Laurence J. O’Toole, Jr. 2002. "Public Management and Organizational Performance: The Effect of Managerial Quality." Journal of Policy Analysis and Management 21 (4): 629-643.

Moynihan, Donald P. and Sanjay K. Pandey. 2005. "Testing How Management Matters in an Era of Government by Performance Management." Journal of Public Administration Research and Theory 15 (3): 421-439.

Moynihan, Donald P and Noel Landuyt. 2008. "Explaining Turnover Intention in State Government Examining the Roles of Gender, Life Cycle, and Loyalty", Review of Public Personnel Administration, 28 (2): 120-143,

Norburn, David and Sue Birley. 1988. The Top Management Team and Corporate Performance. Strategic Management Journal 9(3): 225-37.

Osborne, David and Peter Hutchinson. 2004. The Price of Government: Getting the Results We Need in an Age of Permanent Fiscal Crisis. New York: Basic Books.

O'Toole, Laurence J. Jr. and Kenneth J. Meier. 1999. Modeling the Impact of Public Management: Implications of Structural Context. Journal of Public Administration Research and Theory 9(4): 505-26.

O’Toole, Laurence J. Jr. and Kenneth J. Meier. 2003. Plus ça Change: Public Management, Personnel Stability, and Organizational Performance. Journal of Public Administration Research and Theory 13(1): 43-64.

Rainey, Hal and James Thompson. 2006. Leadership and the Transformation of a Major Institution: Charles Rosetti and the Internal Revenue Service. Public Administration Review 66(4): 596-604.

Riccucci, Norma M. 1995. Unsung Heroes: Federal Execucrats Making a Difference. Washington, DC: Georgetown University Press. 
Shen, Wei and Albert Cannella. 2002. Revisiting the Performance Consequences of CEO Succession: The Impacts of Successor Type, Postsuccession Senior Executive Turnover, and Departing CEO Tenure. Academy of Management Journal 45(4): 717-33.

Staw, Barry M., Lance E. Sandelands, and Jane E. Dutton. 1981. Threat-Rigidity Effects in Organizational Behavior: A Multilevel Analysis. Administrative Science Quarterly 26(4): 501-24.

Stoker, Gerry. 2004. Transforming Local Governance: From Thatcherism to New Labour. Basingstoke: Palgrave Macmillan.

Terry, Larry D. 1995. Leadership of Public Bureaucracies: The Administrator as Conservator. Thousand Oaks, CA: Sage.

Warner, Jerold B., Ross L. Watts, and Karen H. Wruck. 1988. Stock Prices and Top Management Changes. Journal of Financial Economics 20:461-92.

Williams, Brian and Ed Kellough. 2006. Leadership with an Enduring Impact: The Legacy of Chief Burtell Jefferson of the Metropolitan Police Department of Washington D.C. Public Administration Review 66(4): 813-22.

Wilson, David and Chris Game. 2006. Local Government in the United Kingdom. $4^{\text {th }}$ edition. Basingstoke: Palgrave Macmillan. 


\section{Tables $^{9}$}

Table 1: coefficients/marginal effects of the TMT turnover rate on the core service performance score (CSP score) (drawn from unmoderated models where the turnover rate enters linearly)

\begin{tabular}{lll}
\hline \hline & $(1.1)$ & $(1.2)$ \\
\hline TMT turnover rate t-1 & $0.99(0.70)$ & $-0.78(-0.55)$ \\
TMT turnover rate t-2 & & \\
\hline Coefficients on control variables: & $\mathbf{0 . 3 8}(\mathbf{3 . 2 7})$ & $\mathbf{0 . 4 0}(\mathbf{3 . 3 3})$ \\
Lagged CSP score & $-0.03(-0.04)$ & $0.88(1.13)$ \\
Chief executive succession (dummy) & $\mathbf{3 . 0 5}(\mathbf{6 . 8 6})$ & $\mathbf{3 . 0 7}(\mathbf{6 . 6 9 )}$ \\
Year dummy for 2004 & $\mathbf{- 1 . 8 8 ( - 2 . 4 8 )}$ & $\mathbf{- 2 . 0 0}(\mathbf{- 2 . 6 4 )}$ \\
Year dummy for 2005 & $-0.14(0.56)$ & $-0.09(-0.34)$ \\
Constant & $<.0001$ & $<.0001$ \\
\hline$p$-value of general F-test & 431 & 426 \\
No. of obs. & 148 & 148 \\
No. of local governments & $(148$ &
\end{tabular}

Marginal effects are listed, with Huber-White z-statistics (adjusted for clustering on local government) in parentheses. To ease interpretation, all marginal effects that are statistically significant at the $90 \%$ level or better $(|z|>1.645)$ are shaded bold.

Table 2: coefficients/marginal effects of the TMT turnover rate on the Comprehensive Performance Assessment (CPA-treated as an interval variable)

(drawn from unmoderated models where the turnover rate enters linearly)

\begin{tabular}{|c|c|c|}
\hline & $(2.1)$ & $(2.2)$ \\
\hline TMT turnover rate $\mathrm{t}-1$ & $-0.09(-0.47)$ & \\
\hline TMT turnover rate $\mathrm{t}-2$ & & $0.07(0.37)$ \\
\hline \multicolumn{3}{|l|}{ Coefficients on control variables: } \\
\hline Lagged CPA score & $0.66(6.03)$ & $0.65(5.63)$ \\
\hline Chief executive succession (dummy) & $-0.14(-1.57)$ & $0.13(1.47)$ \\
\hline Year dummy for 2004 & $0.20(3.58)$ & $0.19(3.49)$ \\
\hline Year dummy for 2005 & $-0.12(-1.82)$ & $-0.11(-1.68)$ \\
\hline Constant & $0.10(4.31)$ & $0.10(4.32)$ \\
\hline$p$-value of general F-test & $<.0001$ & $<.0001$ \\
\hline No. of obs. & 431 & 426 \\
\hline No. of local governments & 148 & 148 \\
\hline
\end{tabular}

Marginal effects are listed, with Huber-White z-statistics (adjusted for clustering on local government) in parentheses. To ease interpretation, all marginal effects that are statistically significant at the $90 \%$ level or better $(|z|>1.645)$ are shaded bold.

\footnotetext{
${ }^{9}$ Note: all models are autoregressive, estimated by Anderson-Hsiao, and control for fixed differences between local governments as well as individual years.
} 
Table 3: marginal effects of the TMT turnover rate on the core service performance score (CSP score) (drawn from multiplicative models where the turnover rate interacts with baseline performance)

\begin{tabular}{|c|c|c|c|}
\hline & & (3.1) & $(3.2)$ \\
\hline Marginal effects: & Baseline perf. & & \\
\hline \multirow[t]{3}{*}{ TMT turnover rate $\mathrm{t}-1$} & High & $-3.13(-1.20)$ & \\
\hline & Medium & $1.65(1.09)$ & \\
\hline & Low & $1.59(0.39)$ & \\
\hline \multirow[t]{3}{*}{ TMT turnover rate $\mathrm{t}-2$} & High & & $-13.6(-3.47)$ \\
\hline & Medium & & $-0.21(-0.13)$ \\
\hline & Low & & $8.25(1.95)$ \\
\hline
\end{tabular}

Raw coefficients:

TMT turnover rate $\mathrm{t}-1$

$1.65(1.09)$

TMT turnover rate $\mathrm{t}-2$

\begin{tabular}{|c|c|}
\hline & $-0.21(-0.13)$ \\
\hline $0.40(2.98)$ & $0.48(3.58)$ \\
\hline$-4.79(-1.68)$ & $-13.37(-3.18)$ \\
\hline$-0.07(-0.02)$ & $8.46(2.01)$ \\
\hline $0.02(0.02)$ & $0.71(0.90)$ \\
\hline $3.02(6.79)$ & $3.12(6.66)$ \\
\hline$-1.87(-2.33)$ & $-1.92(-2.48)$ \\
\hline$-0.17(-0.69)$ & $-0.07(-0.28)$ \\
\hline$<.0001$ & $<.0001$ \\
\hline 431 & 426 \\
\hline 148 & 148 \\
\hline
\end{tabular}

\section{Lagged CSP score}

TMT turnover rate $\times$ high baseline perf.

TMT turnover rate $\times$ low baseline perf.

Chief executive succession (dummy)

Year dummy for 2004

Year dummy for 2005

Constant

$0.48(3.58)$

p-value of general F-test

No. of obs.

No. of local governments

Marginal effects are listed, with Huber-White z-statistics (adjusted for clustering on local government) in parentheses. To ease interpretation, all marginal effects that are statistically significant at the $90 \%$ level or better $(|z|>1.645)$ are shaded bold.

Table 4: marginal effects of the TMT turnover rate on the Comprehensive Performance Assessment (CPA-treated as an interval variable) (drawn from multiplicative models where the turnover rate interacts with baseline performance)

\begin{tabular}{|c|c|c|c|}
\hline & & $(4.1)$ & $(4.2)$ \\
\hline Marginal effects: & Baseline perf. & & \\
\hline \multirow[t]{3}{*}{ TMT turnover rate $\mathrm{t}-1$} & High & $-1.23(-3.58)$ & \\
\hline & Medium & $-0.30(-1.13)$ & \\
\hline & Low & $1.16(2.16)$ & \\
\hline \multirow[t]{3}{*}{ TMT turnover rate $\mathrm{t}-2$} & High & & $-1.43(-4.30)$ \\
\hline & Medium & & $0.04(0.14)$ \\
\hline & Low & & $1.65(5.05)$ \\
\hline \multicolumn{4}{|l|}{ Raw coefficients: } \\
\hline TMT turnover rate $\mathrm{t}-2$ & & & $0.04(0.14)$ \\
\hline \multicolumn{4}{|l|}{ Lagged CPA } \\
\hline & & $0.81(6.60)$ & $\begin{array}{l}\mathbf{0 . 8 5}(\mathbf{6 . 9 3 )} \\
-1.47(-3.89)\end{array}$ \\
\hline \multicolumn{2}{|c|}{$\begin{array}{l}\text { TMT turnover rate } \times \text { high baseline perf. } \\
\text { TMT turnover rate } \times \text { low baseline perf. }\end{array}$} & $\begin{array}{l}-0.93(-2.54) \\
1.45(2.45)\end{array}$ & $1.61(3.50)$ \\
\hline \multicolumn{2}{|c|}{ Chief executive succession (dummy) } & $-0.20(-1.95)$ & $0.12(1.34)$ \\
\hline \multicolumn{2}{|l|}{ Year dummy for 2004} & $0.17(3.03)$ & $0.23(3.81)$ \\
\hline \multicolumn{2}{|l|}{ Year dummy for 2005} & $-0.18(-2.57)$ & $-0.10(-1.57)$ \\
\hline \multicolumn{2}{|l|}{ Constant } & $0.10(4.12)$ & $0.09(3.84)$ \\
\hline \multicolumn{2}{|l|}{ p-value of general F-test } & $<.0001$ & $<.0001$ \\
\hline \multicolumn{2}{|l|}{ No. of obs. } & 431 & 426 \\
\hline \multicolumn{2}{|c|}{ No. of local governments } & 148 & 148 \\
\hline
\end{tabular}

Marginal effects are listed, with Huber-White z-statistics (adjusted for clustering on local government) in parentheses. To ease interpretation, all marginal effects that are statistically significant at the $90 \%$ level or better $(|z|>1.645)$ are shaded bold. 
Table A1: summary statistics

\begin{tabular}{|c|c|c|c|c|}
\hline & Mean & Standard deviation & Minimum & "Maximum \\
\hline $\begin{array}{l}\text { Core service performance score } \\
\text { (CSP) }\end{array}$ & 69.65 & 8.44 & 40 & 90 \\
\hline $\begin{array}{l}\text { Comprehensive Performance } \\
\text { Assessment (CPA) }\end{array}$ & 2.95 & 0.87 & 0 & 4 \\
\hline Turnover rate $\mathrm{t}-1$ & 0.19 & 0.21 & 0 & 1 \\
\hline Turnover rate $\mathrm{t}-2$ & 0.18 & 0.20 & 0 & 1 \\
\hline $\begin{array}{l}\text { Chief executive succession } \\
\text { (dummy) t-1 }\end{array}$ & 0.17 & 0.38 & 0 & 1 \\
\hline $\begin{array}{l}\text { Chief executive succession } \\
\text { (dummy) } t-2\end{array}$ & 0.16 & 0.36 & 0 & 1 \\
\hline
\end{tabular}

The summary statistics cover the estimation sample of the CSP models (431 observations on 148 local governments). The estimation sample of the CPA models (426 observations on the same 148 local governments) is a proper subset of the CSP models estimation sample.

Table A2: alternative specifications of the Comprehensive Performance Assessment (CPA)

\begin{tabular}{|c|c|c|c|}
\hline & Models discussed in the article & Alternative 1 & Alternative 2 \\
\hline low baseline performance & 0 stars (Poor) or 1 star (Weak) & $\begin{array}{l}0 \text { stars (Poor), } 1 \text { star (Weak), or } 2 \text { stars } \\
\text { (Fair) }\end{array}$ & 0 stars (Poor) or 1 star (Weak) \\
\hline medium baseline performance & 2 stars (Fair) or 3 stars (Good) & 3 stars (Good) & 2 stars (Fair) \\
\hline high baseline performance & 4 stars (Excellent) & 4 stars (Excellent) & 3 stars (Good) or 4 stars (Excellent) \\
\hline
\end{tabular}

Table A3: marginal effects of the TMT turnover rate on the Comprehensive Performance Assessment (CPA-treated as an interval variable)

(drawn from multiplicative models where the turnover rate interacts with baseline performance)

\begin{tabular}{|c|c|c|c|c|c|c|c|}
\hline & Baseline perf. & $\begin{array}{c}\text { Models discussed in } \\
\text { the article }\end{array}$ & Alternative 1 & Alternative 2 & $\begin{array}{l}\text { Models discussed in } \\
\text { the article }\end{array}$ & Alternative 1 & Alternative 2 \\
\hline \multirow[t]{3}{*}{ TMT turnover rate $\mathrm{t}-1$} & High & $-1.23(-3.58)$ & $-1.07(-3.47)$ & $-0.42(-1.49)$ & & & \\
\hline & Medium & $-0.30(-1.13)$ & $-0.13(-0.45)$ & $-0.63(-1.93)$ & & & \\
\hline & Low & $1.16(2.16)$ & $0.34(1.13)$ & $1.11(2.12)$ & & & \\
\hline \multirow[t]{3}{*}{ TMT turnover rate $\mathrm{t}-2$} & High & & & & $-1.43(-4.30)$ & $-1.33(-4.16)$ & $-0.52(-1.96)$ \\
\hline & Medium & & & & $0.04(0.14)$ & $-0.08(-0.31)$ & $0.13(0.28)$ \\
\hline & Low & & & & $1.65(5.05)$ & $0.72(2.59)$ & $1.61(5.06)$ \\
\hline
\end{tabular}

Marginal effects are listed, with Huber-White z-statistics (adjusted for clustering on local government) in parentheses. To ease interpretation, all marginal effects that are statistically significant at the $90 \%$ level or better $(|z|>1.645)$ are shaded bold.

Note: all models are autoregressive, estimated by Anderson-Hsiao, and control for fixed differences between local governments as well as individual years. 
Figure A1: Marginal effect of the top management team turnover rate with baseline performance as a continuous moderating variable

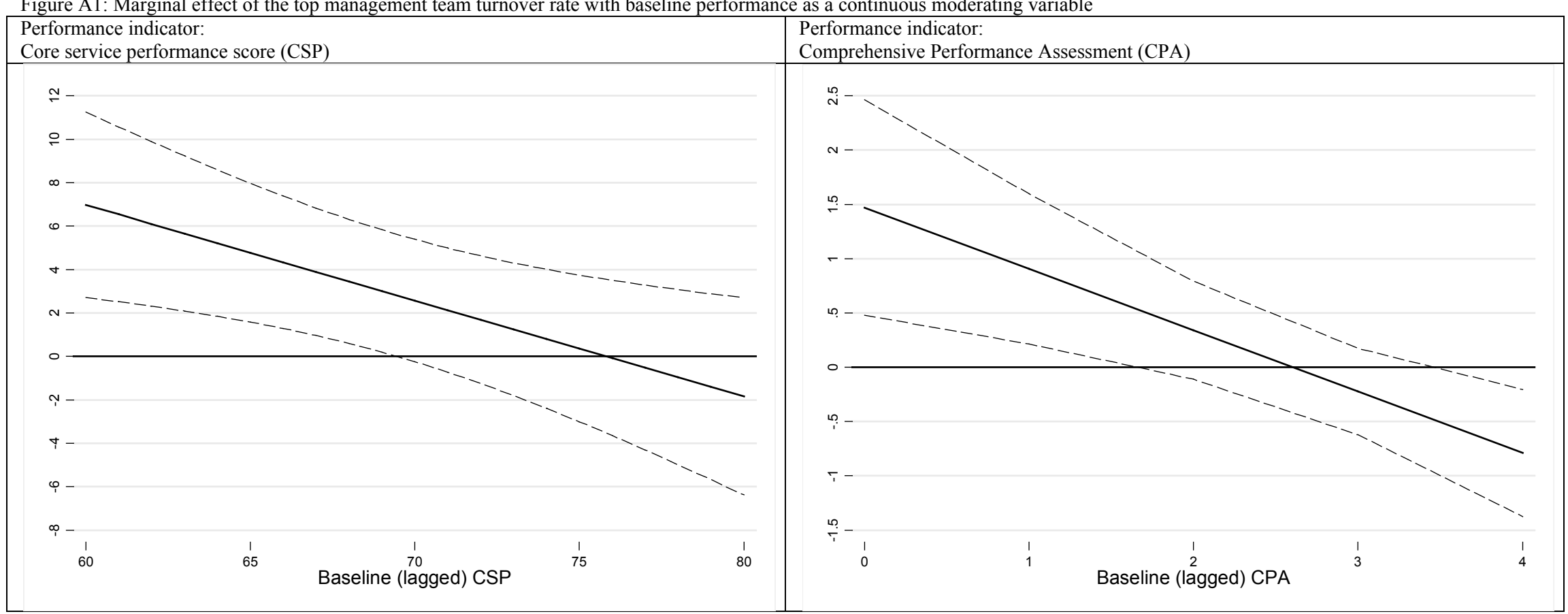

The specifications estimated here are:

Performance $_{i t}=b 0+b 1$ performance $_{i, t-1}+b 2$ turnover rate $_{i, t-1}$

$+\mathrm{b} 3$ (turnover rate $\times$ performance) $i_{i, t-1}+u_{i}+\varepsilon$ it,

where performance is the CSP in the left-hand panel and the CPA in the right-hand panel of the figure. The graphs show the estimated marginal effect of the top management team turnover rate (the partial derivative of the above equation with respect to the turnover rate). In the left-hand panel graph (CSP), the marginal effect is plotted from the tenth percentile (60) to the $90^{\text {th }}$ percentile (80) of the moderating variable, the CSP. In the right-hand panel graph (CPA), the marginal effect is plotted across the range of the moderating variable, the CPA, from 0 to 4 . The different values of the moderating variable, baseline performance are on the $\mathrm{x}$-axis and the size of the marginal effect of the top management team turnover rate is on the $y$-axis. The solid descending line is the estimated marginal effect and the dashed bands around it make up the $90 \%$ confidence interval.

Both panels of the figure show that, for low baseline performance, our finding of a performance increase following an increase in the top management team turnover rate holds up when we use a continuous moderating variable. To be able to directly compare the effects of top management team turnover at high and low levels of baseline performance, as suggested by our hypotheses, we use dummies for high and low baseline performance as moderators in the main text of the article. 